\title{
Bilateral Posterior Uveitis Due to Syphilis
}

\author{
Sifilize Bağlı Bilateral Posterior Üveit
}

\author{
(1) Ali llgın OLUT' ${ }^{1}$, (1) Selma TOSUN ${ }^{1}$, (1) Levent SAĞBAN ${ }^{2}$, (1) Alpay ARI ${ }^{1}$, (1) Nihat TÜRKAN ${ }^{1}$ \\ ${ }^{1}$ Izmir Bozyaka Training and Research Hospital, Clinic of Infectious Diseases and Clinical Microbiology, izmir, Turkey \\ ${ }^{2}$ Izmir Bozyaka Training and Research Hospital, Clinic of Ophthalmology, Izmir, Turkey
}

Keywords: Ocular syphilis, neurosyphilis, uveitis, penicillin G, Trepnema pallidum

Anahtar Kelimeler: Oküler sifiliz, nörosifiliz, üveit, penisilin G, Treponema pallidum

\section{Dear Editor,}

Approximately half of the cases of uveitis are idiopathic and the other half is caused by either an autoimmune disease or an infection. The most common autoimmune disorders causing autoimmune uveitis are Behçet's disease, Reiter's syndrome and ankylosing spondylitis. Infections are responsible from 20\% of all uveitis cases. The most common etiological agents are herpes simplex viruses (HSVs) and toxoplasmosis followed by cytomegalovirus (CMV), toxocariasis, tuberculosis and syphilis ${ }^{[1]}$. Ocular involvement of syphilis tends to occur in secondary and more often in latent and late stages of the disease although very rarely it may occur in the primary stage of the infection. Ocular syphilis is a rare complication of syphilis accounting for less than $1 \%$ of syphilis cases but this rate may reach up to $5 \%$ in patients progressing to tertiary stage ${ }^{[2]}$. In up to $40 \%$ of cases, concomitant neurosyphilis may be present ${ }^{[3] .}$ All parts of the eye may be affected, but uveitis is the most common manifestation and typically ocular syphilis is a granulomatous type posterior or panuveitis. However, isolated anterior uveitis is more frequent. Syphilitic uveitis may be bilateral affecting both eyes in approximately $60-75 \%$ of all cases $^{[4]}$. Prompt recognition and management is necessary as approximately $10 \%$ of affected patients have permanent vision $\operatorname{loss}^{[5]}$. Here, we describe a case of a patient with ocular syphilis who presented with bilateral posterior uveitis, retinal vasculitis and optic neuropathy.

A 60-year-old male patient presented to our Ophtalmology clinic with the complaint of visual impairment in both eyes for three weeks. His medical and family history was unremarkable except for antidepressant medications use for the last five years. On the ophthalmic examination, the best-corrected visual acuity was 40/200 in the right and finger counting in the left eye. On fundus examination, he was diagnosed as having bilateral posterior uveitis, bilateral optic disc edema and retinal vasculitis (Figure 1, 2). He was consulted to Rheumatology Department while all autoimmune screening tests were found to be negative. He was prescribed oral and topical steroids and discharged. A follow-up visit was scheduled for two weeks after discharge. At his second visit, he complained of a progressive decline in vision. He was consulted to the Chest Diseases where sarcoidosis and tuberculosis were ruled out and than he was referred to our infectious diseases unit.

For screening of infectious etiologies, serological studies were performed and HSV, toxoplasmosis, varicella zoster virus, CMV, rubella, brucella and HIV tests were all found to be nonreactive whereas Trepanoma pallidum particle agglutination (TP-PA) and Venereal Disease Research Laboratory test (VDRL-RPR) (OMEGA

Cite this article as: Olut Al, Tosun S, Sağban L, Arı A, Türkan N. Bilateral Posterior Uveitis Due to Syphilis. Mediterr J Infect Microb Antimicrob. $2018 ; 7: 16$. 


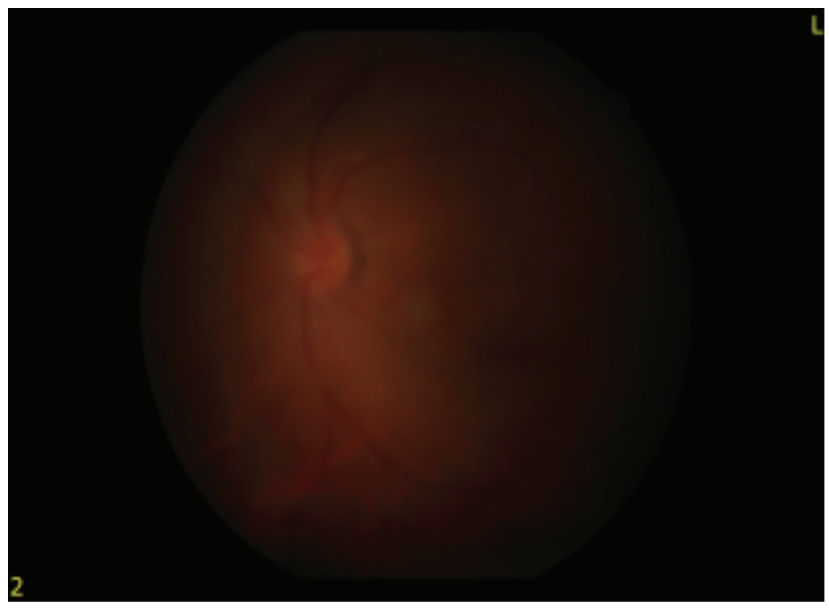

Figure 1. Fundoscopic examination shows diffuse vitritis obstructing to visualize fundus clearly

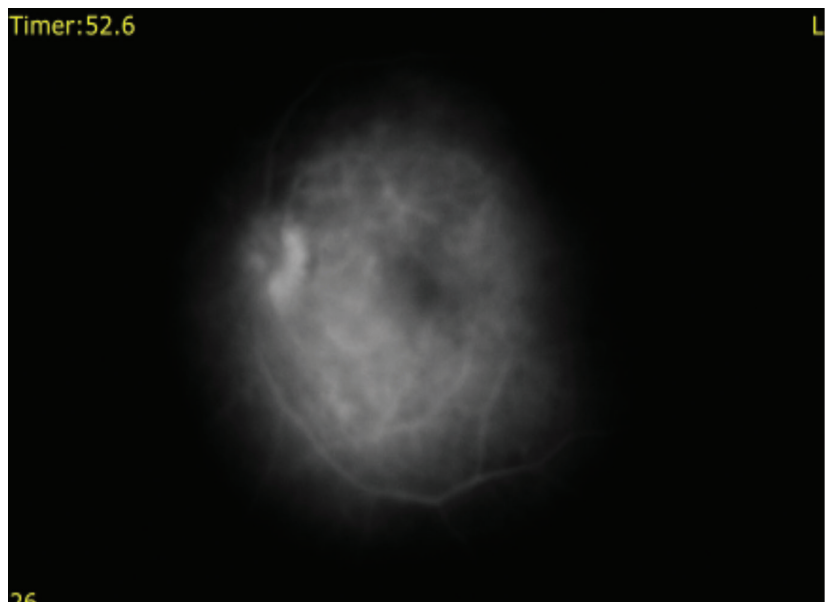

Figure 2. Fundus fluorescein angiography of the left eye showing, leakage from retinal vessels, staining of the optic nerve and macullary edema

Diagnostics, United Kingdom) were found to be positive at a titer of $1: 1280$. His detailed history revealed multiple heterosexual partners with inconsistent barrier/condom use until last year, when his psychological status started to deteriorate and antipsychotic medication was started. He had no signs of any syphilitic lesion on examination and denied previous history of genital ulcer, skin rash and syphilis or any other sexually transmitted disease. Before starting therapy, a lumbar puncture was performed and cerebrospinal fluid (CSF) findings were as follows: protein - $41 \mathrm{mg} / \mathrm{dL}$, glucose - $80 \mathrm{mg} / \mathrm{dL}$, WBC - 30/mL (80\% PNLs, 20\% lymphocytes), and a negative bacterial culture and positive VDRL test. Treatment with intravenous (IV) penicillin $4 \times 6$ million $\mathrm{U} /$ day that lasted 14 days and concomitant steroid (oral prednisone $60 \mathrm{mg}$ daily and tapered over days) was started to avoid Jarisch-Herxheimer reaction that may occur in up to one third of patients treated by penicillin for neurosyphilis. The patient's status rapidly improved and visual acuity at discharge was 40/200 in the right eye and 20/200 in the left eye. One month after discharge, eye examination of the patient revealed a visual acuity of 60/200 in right and 60/200 in the left eye; the number of the cells at the vitreous body was markedly decreased but bilateral disc edema was the same. He had a positive VDRLRPR titer of $1 / 320$.

Syphilis is an uncommon disease but the incidence is currently increasing mainly due to alterations in sexual behavior, especially in men who have sex with men and due to increase in the number of HIV (+) patients. Although ocular syphilis is a rare complication of the disease, there are many cases initially diagnosed by ocular invasion. Actually, due to new appearing cases, the Centers for Disease Control and Prevention (CDC) issued recommendations in 2005, and since then over 200 new cases of ocular syphilis have been reported in the USA indicating a marked increase in the incidence ${ }^{[6]}$. Ocular syphilis is very rarely reported from our country. In the literature, we found two cases, one was bilateral uveitis the other was unilateral uveitis accompanied by chorioretinitis. Both patients were antiHIV negative but the immune statuses of the patients were not described $^{[7,8]}$.

Ocular syphilis may affect every part of the eye. The CDC defined ocular syphilis as syphilis at any stage plus signs of ocular disease that include uveitis, panuveitis, optic neuropathy, interstitial keratitis, anterior uveitis and retinal vasculitis, but still the most common presentations are reported to be panuveitis or posterior uveitis ${ }^{[9]}$. According to the CDC Sexually Transmitted Diseases Treatment Guidelines, 2015, neurosyphilis and ocular syphilis are treated with aqueous crystalline penicillin G 18-24 million units per day, administered as 3-4 million units IV every 4 hours or continuous infusion for 10-14 days ${ }^{[9]}$. The accurate diagnosis is made by clinical findings and serological tests. A VDRL-RPR test that is widely used for screening and monitoring of the activity of the disease is actually not very sensitive or specific especially in late phases (late, latent, tertiary). As ocular syphilis is typically a complication of secondary or late syphilis, the results of TP-PA and/or fluorescent treponemal antibody absorption test (FTA-ABS) should also be obtained. In series of 50 patients with a reactive FTA-ABS and eye findings consistent with ocular syphilis, VDRL test was reactive in only $24 \%$ of patients $^{[3]}$. In a report by Moradi et al. ${ }^{[10]}$, in 35 cases of ocular syphilis, only two thirds of the patients were VDRL-RPR (+) while all patients had positive FTA-ABS results.

All ocular syphilis cases should be considered a type of neurosyphilis. In a study by Dai et al. ${ }^{[4]}$, among 25 HIV-negative ocular syphilis cases, CSF abnormalities were found in $72 \%$ of patients: $60 \%$ had elevated white blood cell count, 52\% had elevated protein level, and 36\% had reactive CSF in VDRL test.

Our case reflects a typical presentation of ocular syphilis in an immune competent patient with bilateral invasion of the 
posterior uvea, a positive serology for VDRL-RPR and TP-PA, and well response to IV penicillin treatment. Prompt recognition of the situation is important since a delay in starting treatment might result in ocular morbidity and permanent vision loss.

\section{Ethics}

Informed Consent: No need.

Peer-review: Externally and internally peer-reviewed.

\section{Authorship Contributions}

Surgical and Medical Practices: L.S., Concept: A.I.O., Design: A.I.O., S.T., Data Collection or Processing: A.I.O., A.A., Analysis or Interpretation: A.I.O., S.T., A.A., Literature Search: N.T., Writing: A.I.O.

Conflict of Interest: No conflict of interest was declared by the authors.

Financial Disclosure: The authors declared that this study received no financial support.

\section{References}

1. Rodriguez A, Calonge M, Pedroza-Seres M, Akova YA, Messmer EM, D'Amico DJ, Foster CS. Referral patterns of uveitis in a tertiary eye care center. Arch Ophthalmol. 1996;114:593-9.
2. Benson CE, Soliman MK, Knezevic A, Xu DD, Nguyen QD, Do DV. Bilateral papillitis and unilateral focal chorioretinitis as the presenting features of syphilis. J Ophthalmic Inflamm Infect. 2015;5:16.

3. Spoor TC, Ramocki JM, Nesi FA, Sorscher M. Ocular syphilis 1986. Prevalence of FTA-ABS reactivity and cerebrospinal fluid findings. J Clin Neuroophthalmol. 1987;7:191-5.

4. Dai T, Wu X, Zhou S, Wang Q, Li D. Clinical manifestations and cerebrospinal fluid status in ocular syphilis in HIV-Negative patients. BMC Infect Dis. 2016;16:245.

5. Amaratunge BC, Camuglia JE, Hall AJ. Syphilitic uveitis: a review of clinical manifestations and treatment outcomes of syphilitic uveitis in human immunodeficiency virus-positive and negative patients. Clin Exp Ophthalmol. 2010;38:68-74.

6. Clinical Advisory: Ocular Syphilis in the United States. 2015 Last accessed date: 01.03.2018 Available from: http://.www.cdc.gov/std/ syphilis/clinicaladvisoryos2015.htm

7. Akincioglu D, Özgönül C, Gökçe G, Durukan AH. A Case of Acute Bilateral Syphilitic Uveitis. Turk J Ophthalmol. 2015;45:122-4.

8. Altın A, Çınar P, Fırıcıoğulları E, Zorlu F. An ocular syphilis case with uveitis and multifocal chorioretinitis. Turkiye Klinikleri J Ophthalmol. 2008;17:5761.

9. Centers for Disease Control and Prevention. Sexually Transmitted Disease Surveillance, 2014. Atlanta: US Department of Health and Human Sciences; 2015.

10. Moradi A, Salek S, Daniel E, Gangaputra S, Ostheimer TA, Burkholder BM, Leung TG, Butler NJ, Dunn JP, Thorne JE. Clinical features and incidence rates of ocular complications in patients with ocular syphilis. Am J Ophthalmol. 2015; 159:334-43. 